\title{
Does Industry 4.0 Have the Same Impact on Employment in the Sectors?
}

\author{
ROMAN CHINORACKÝ \\ University of Zilina, Slovakia \\ roman.chinoracky@fpedas.uniza.sk \\ STANISLAVA TURSKÁ \\ University of Zilina, Slovakia \\ stanislava.turska@fpedas.uniza.sk \\ LUCIA MADLEŇÁKOVÁ \\ University of Zilina, Slovakia \\ lucia.madlenakova@fpedas.uniza.sk
}

Digital transformation is the driving force of the present and near future. Scientific and technological advances make digital transformation change not only societies and businesses, but also entire national economies. This digital transformation is also referred to as the so-called fourth industrial revolution (Industry 4.0), which is in terms of technological progress directly follows previous industrial revolutions. All previous industrial revolutions influenced the labour market and changed the nature of the professions. That's why the primary goal of this paper is to analyse the impact of Industry 4.0 on the labour market. In order to achieve this goal we have analysed the work of several authors and studies and enhanced it with the analysis of our own. Our own research was dedicated to answering the research question: Does the fourth industrial revolution have the same impact on employment in the same sectors of the national economies of the selected countries? In order to answer this question we used the correlation analysis to measure correlation coefficients between risk of job automation and employment in sectors of agriculture, services and industry in selected oECD countries. The main conclusions drawn from this paper are that risk of job automation in countries increases when their employment in sectors of agriculture and industry is relatively high and on the other hand this risk decreases when employment in sector of services is high.

Key words: industry 4.o, digital transformation, employment, labour market

https://doi.org/10.26493/1854-4231.14.5-17

\section{Introduction}

Digital transformation is the driving force of present and near future. Scientific and technological advances make digital transformation 
change not only societies and businesses, but also entire national economies. The term digital transformation is often associated with the fourth industrial revolution. All previous industrial revolutions influenced labour market and changed the nature of the professions. This is also the case for the fourth industrial revolution.

\section{Literature Review}

The fourth industrial revolution follows three previous industrial revolutions. The first industrial revolution was triggered by the construction of railroads and the invention of the steam engine, which ushered in mechanical production. The second industrial revolution made mass production possible and was fostered by the advent of electricity and the assembly line. Third industrial revolution preceded fourth industrial revolution and is usually called the computer or digital revolution because it was catalysed by the development of semiconductors, mainframe computing, personal computing and the internet (Schwab 2016).

The term 'fourth industrial revolution' originally initiated in Germany and is also frequently referred to as Industry 4.o. Industry 4.0 can be defined as the integration of complex physical machinery and devices with networked sensors and software, used to predict, control and plan for better business and societal outcomes (Industrial Internet Consortium 2017). Another view refers to this term as the adoption of computers and automation which are enhanced with smart and autonomous systems fuelled by data and machine learning. (Marr 2018) In general Industry 4.0 serves as an important model to companies around the world for the vertical integration of smart machines, products and production resources into flexible manufacturing systems (Kagermann et al. 2016) and connects technologies and smart production processes to pave the way to a new technological age which will radically transform industry, production value chains and business models (Germany Trade \& Invest 2014).

We're living in a time of astonishing progress with digital technologies - those that have computer hardware, software, and networks at their core. Computers are going to continue to improve and to do new and unprecedented things. The key building blocks are already in place for digital technologies to be as important and transformational and in short, we are entering a second machine age (Brynjolfsson and McAfee 2014). The current technological change offer some radical new opportunities that can lead to significant transformations not only in the way of producing and doing business but 
also in the overall economic system (Brynjolfsson and McAfee 2014; Rifkin 2014).

Dramatic improvements in technology allow automating an increasing number of tasks and occupations. For this reason, there is a widespread concern that new technologies might destroy a large number of jobs and cause 'technological unemployment.' The threat of displacement is believed to be particularly strong with industrial robots, because they are explicitly designed to perform tasks that would otherwise be performed by humans (OECD 2018). The accelerated automation of tasks performed by labour raises concerns that new technologies will make labour redundant and in destructive way can render entire professions obsolete (Autor 2015; Kotynkova 2016).

Automation always has aimed and always will aim to substitute for human labour, and with new robotic concepts ahead we will see many attempts to do so in the world of routine based work (Pfeiffer 2016). However automation also complements labour, raises output in ways that lead to higher demand for labour, and interacts with adjustments in labour supply (Autor 2015). In the past, industrial revolutions triggered structural transformations, which, after recovering from initial technological unemployment, have brought mankind merely frictional unemployment, and prosperity rather than poverty, and it remains to be seen whether it is different this time (Mokyr, Vickers, and Ziebarth, 2015). There is also no consensus among scholars on the future effective capacity of robots and industry 4.0 technologies to fully substitute for human labour, as there are some skills such as flexibility, judgement and common sense or the ability to identify the purposiveness of objects that so far showed to belong exclusively to human skills. Technological progress associated with Industry 4.0 also raises the question of the best possible cooperation between humans and machines (Freddi 2018, Trompisch 2017).

\section{Analysis of Current State}

Today, as industrial robots, digital technologies, computer controlled machines and artificial intelligence replace labour, we are again witnessing the emergence of new tasks ranging from engineering and programming functions to those performed by audio-visual specialists, executive assistants, data administrators and analysts, meeting planners, and social workers (Acemoglu and Restrepo 2018).

The main challenge in the estimation of the number of jobs at risk of automation is the definition of which tasks are actually subject to automation. Several studies attempted to tackle this problem. The 
commonly cited study which is also referred to by the OECD (2018) is from Frey and Osborne (2013). Jobs that require the following skills are considered to be safe from automation:

- Tasks linked to perception and manipulation, especially if they require being involved in unstructured processes such as working in cramped workspaces.

- Tasks that require creativity, such as artistic activities or coming up with original ideas.

- Tasks that rely on social intelligence, such as being persuasive, negotiating aspects of a project or caring for others.

An increasing demand in the period up to the year 2022 should have jobs that are significantly based on and enhanced by the use of technology. Such jobs are for example data analysts, scientists, software and applications developers, ecommerce and social media specialists. Also expected to grow are jobs that leverage distinctively human skills, knowledge, services, competences, character (Corejova and Al Kassiri 2016). For example customer service workers, sales and marketing professionals, innovation managers and organizational development specialists.

There is also accelerating demand for new jobs which are related to the understanding and leveraging the latest emerging technologies: for example AI and machine learning specialists, big data specialists, process automation experts, information security analysts, robotics engineers, blockchain specialists and user experience and human-machine interaction designers. On the other hand jobs that are expected to be increasingly redundant are routine-based, middle skilled and white collar. Such jobs are for example data entry clerks, accounting and payroll clerks, secretaries, auditors, bank tellers and cashiers. Examples of these jobs are susceptible to advances in new technologies and process automation (World Economic Forum 2018).

There's never been a better time to be a worker with special skills or the right education, because these people can use technology to create and capture value. However, there's never been a worse time to be a worker with only 'ordinary' skills and abilities to offer, because computers, robots, and other digital technologies are acquiring these skills and abilities at an extraordinary rate (Brynjolfsson and McAfee 2014). At present, particular emphasis will be and is placed on information and communications sector (Madudova, Corejova, and Valica 2018) as well as the service sector (Corejova and $\mathrm{Al}$ Kassiri 2015) which can influence overall employment of countries. 


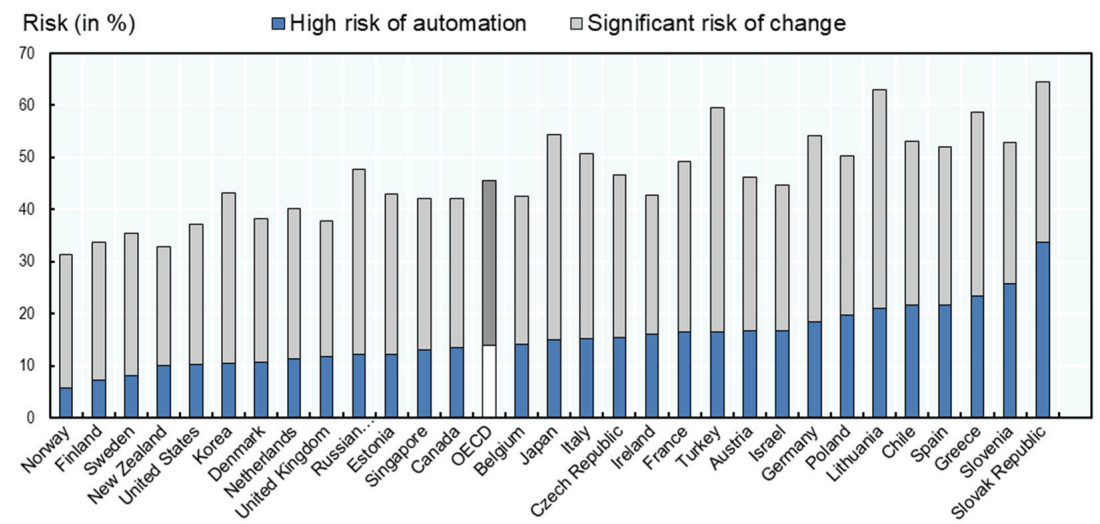

FIGURE 1 Share of Jobs at High and Significant Risk of Automation by Selected Countries of OECD (adapted from OECD 2018)

We can conclude, according to many authors and studies related to this topic that in this digital age the nature of jobs is shifting. Some workers will benefit from new technology that makes their jobs more pleasant and leads to rising wages. Other workers will struggle to adapt to the new environment and will face job losses. Since prospective winners and losers are unevenly distributed within countries, some places will fare better than others (OECD 2018). These prospective winners and losers from the perspective of countries and their labour markets potentially affected by automation can be seen in figure 1 .

The share of jobs at high risk of automation varies strongly across the countries. A job is considered to be at high risk of automation if it has a $70 \%$ or higher probability of being automated. At the significant risk of change are jobs that have 50 to $70 \%$ probability of being automated. As we can see in the figure 1, the percentage of jobs at high risk of automation ranges from 5.7\% in Norway to $33.6 \%$ in Slovakia. In general countries of Northern Europe - Norway, Finland, Sweden; New Zealand and United States face relatively low levels of risk. On the contrary Slovakia, Slovenia and countries of Southern Europe face a much higher risk of automation (OECD 2018).

The differences are not due to sectoral differences in the respective economies. Rather they are due to the different organization of jobs in those countries. Jobs in Southern Europe and Eastern Europe are more likely to have automatable aspects than jobs of the same job family in the other countries. This means that jobs in occupation in the second country are at much lower risk than in the first country (Nedeloska and Quintini 2018). 


\section{Methodology}

The aim of the paper is to analyse the impact of Industry 4.0 and automation on labour market. These impacts were analysed in previous chapter and our goal was to enhance this analysis with the analysis of our own. Our own research was dedicated to the analysis that focused on resolving the question if the job automation can have the same impact on the employment in the same sectors, because as we pointed out according to different authors and studies automation tends to disrupt jobs and bring about technological unemployment. Impacts were analysed on a sample of selected oECD countries for which the study 'Job creation and local economic development 2018' quantified the percentage of jobs that are, according to OECD findings, most vulnerable to automation on labour market in the selected countries (table 1).

To answer this question we have applied correlation analysis. Based upon this analysis we calculated correlation coefficients and determined if there is low, moderate or high correlation and positive or negative linear dependency between variables. In calculating these coefficients, two variables were taken into account. The first variable represented the percentage of jobs threatened by automation in selected countries. The second variable represented the percentage of employment in the primary sector (agriculture), secondary sector (industry) and tertiary sector (services) in the selected countries. Data of employment in the sectors of agriculture, industry and services were obtained from databases of the World Bank. All the data are stated in table 1 and are from the same year 2013.

\section{Results}

The results of the research are stated in the figures 2 to 4 .

Figure 2 shows that the examined variables are positively related and it means that if the one variable is higher also the second one is higher. The correlation coefficient in this case has value of 0.45232 . This means that between the examined variables there is a positive moderate correlation.

According to the figure 2, we can state that in countries such as Slovakia and Slovenia, where there is relatively high employment in the industrial sector, there is also a high degree of jobs that are vulnerable to automation. This means that the employment in industrial sector in these countries can be potentially mostly affected by automation. Norway, Sweden and Finland, which have low employment rate in the industrial sector also have low risk of automation of 
TABLE 1 Sample of Selected Countries

\begin{tabular}{|c|c|c|c|c|}
\hline \multirow[t]{2}{*}{ Country } & \multirow{2}{*}{$\begin{array}{r}\text { Jobs at high risk of } \\
\text { automation (\%) }\end{array}$} & \multicolumn{3}{|c|}{ Employment (\%) } \\
\hline & & Agriculture & Services & Industry \\
\hline Chile (снL) & 21.6 & $9 \cdot 5$ & 66.7 & 23.9 \\
\hline Lithuania (LTU) & 21.1 & 8.4 & 66.1 & $25 \cdot 5$ \\
\hline Israel (ISR) & 16.8 & 1.3 & 80.8 & 17.9 \\
\hline Turkey (TUR) & 16.4 & 22.9 & 50.7 & 26.4 \\
\hline Japan (JPN) & 15.1 & 3.8 & 70.1 & 26.2 \\
\hline Canada (cAN) & $13 \cdot 5$ & 2.1 & 78.1 & 19.8 \\
\hline Korea (KOR) & 10.4 & 6.1 & 69.5 & $24 \cdot 4$ \\
\hline United States (USA) & 10.2 & 1.5 & 79.7 & 18.8 \\
\hline New Zealand (NZL) & 10.0 & 6.4 & $73 \cdot 3$ & 20.3 \\
\hline Finland (FIN) & 7.2 & 4.1 & 73.0 & 22.9 \\
\hline Estonia (EST) & 12.2 & $4 \cdot 3$ & $65 \cdot 5$ & 30.3 \\
\hline Belgium (BEL) & 14.0 & 1.4 & 76.9 & 21.7 \\
\hline France (FRA) & 16.4 & 3.1 & 75.6 & 21.3 \\
\hline Sweden (swE) & 8.0 & 2.0 & 78.8 & 19.2 \\
\hline Ireland (IRL) & $15 \cdot 9$ & $5 \cdot 7$ & 76.1 & 18.2 \\
\hline Denmark (DNK) & 10.7 & 2.5 & 78.0 & 19.5 \\
\hline Norway (NoR) & $5 \cdot 7$ & 2.2 & $77 \cdot 5$ & 20.3 \\
\hline Spain (ESP) & 21.7 & $4 \cdot 3$ & 76.0 & 19.8 \\
\hline United Kingdom (GBR) & 11.7 & 1.1 & 80.1 & 18.9 \\
\hline Netherlands (NLD) & 11.4 & 2.1 & 81.4 & 16.5 \\
\hline Poland (POL) & 19.8 & 12.0 & $57 \cdot 5$ & 30.5 \\
\hline Slovenia (svN) & $25 \cdot 7$ & 8.5 & 60.5 & 31.0 \\
\hline Greece (GRC) & $23 \cdot 4$ & $13 \cdot 7$ & 70.8 & 15.6 \\
\hline Austria (AUT) & 16.6 & 4.6 & $69 \cdot 5$ & 25.9 \\
\hline Germany (DEU) & 18.4 & 1.5 & 70.8 & 27.8 \\
\hline Italy (IтA) & 15.2 & 3.6 & 69.4 & 27.1 \\
\hline Czech Republic (czE) & $15 \cdot 5$ & 3.0 & $59 \cdot 5$ & $37 \cdot 5$ \\
\hline Slovak Republic (svk) & 33.6 & $3 \cdot 3$ & 60.9 & 35.8 \\
\hline
\end{tabular}

jobs and can be potentially least affected by job automation. An Interesting finding is that a country such as the Czech Republic, where employment in the industrial sector is $37.5 \%$, has the risk of job automation at $15.5 \%$. On the contrary, a country like Slovakia, where it is $35.8 \%$ of workforce employed in the industrial sector, has the risk of job automation at $33.6 \%$.

This finding is directly related to the question, that why the correlation coefficient is only moderate. One of the possible explanations we pointed out in the end of chapter 3. For example, workers on an 


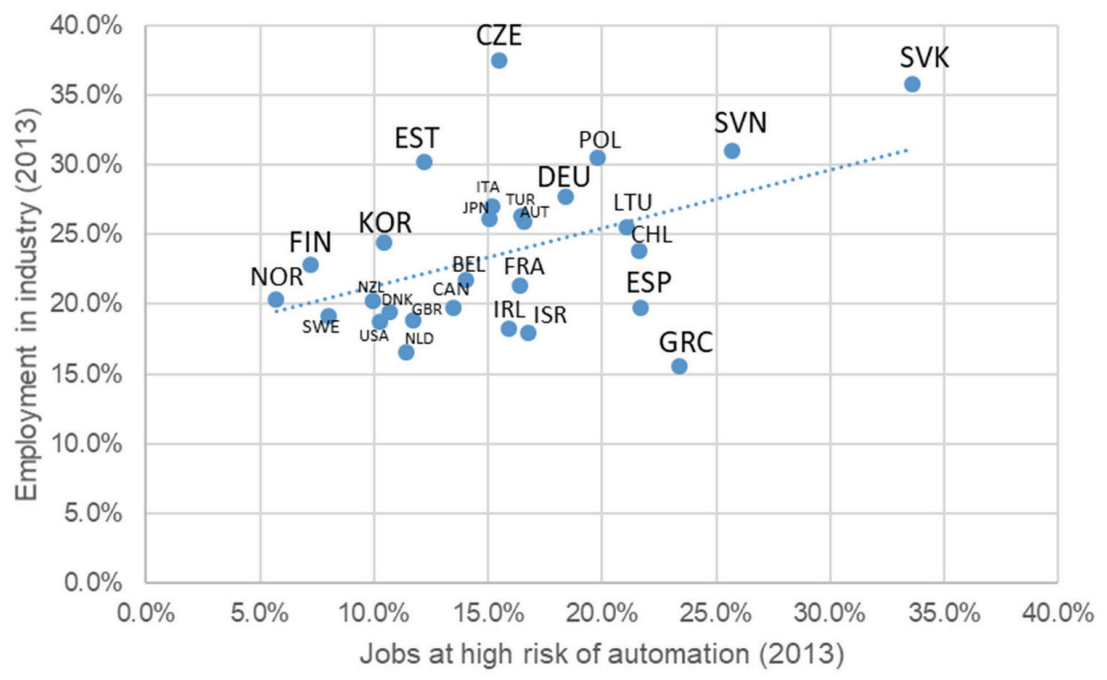

FIGURE 2 Relationship between the Percentage of Jobs at High Risk of Automation and the Percentage of Employment in Industry

assembly line might only do a manual task that is at high risk of automation in one country. In another country, workers in the same occupation might also monitor an industrial robot and take care of quality control measures. In this case, jobs in the occupation in the second country are at much lower risk than in the first country. This means that in the case of Czech Republic there can be a lot of jobs that are partly automated in the industrial sector. And in the case of Slovakia there are more jobs in the industrial sector that can be automated than in Czech Republic.

As we can see in figure 3, the examined variables are negatively related, which means that if one variable is lower, another one is higher. In our case if variable 'percentage of jobs at high risk of automation' is high, variable 'percentage of employment in services' is low. Correlation coefficient in this case has value of -0.52017 and indicates moderate negative correlation between examined variables.

From the point of view of the countries that we examined, we can conclude that in countries where there is under $61 \%$ of employment in service sector there are 2 countries which can be highly affected by automation. In this case, it is Slovakia and Slovenia. On the other hand there are countries who also have relatively low employment in the service sector compared to other countries, but are not that vulnerable to the job automation. Such countries are Czech Republic, Poland and Turkey. This can mean that in Slovakia and Slovenia 
Does Industry 4.o Have the Same Impact ...

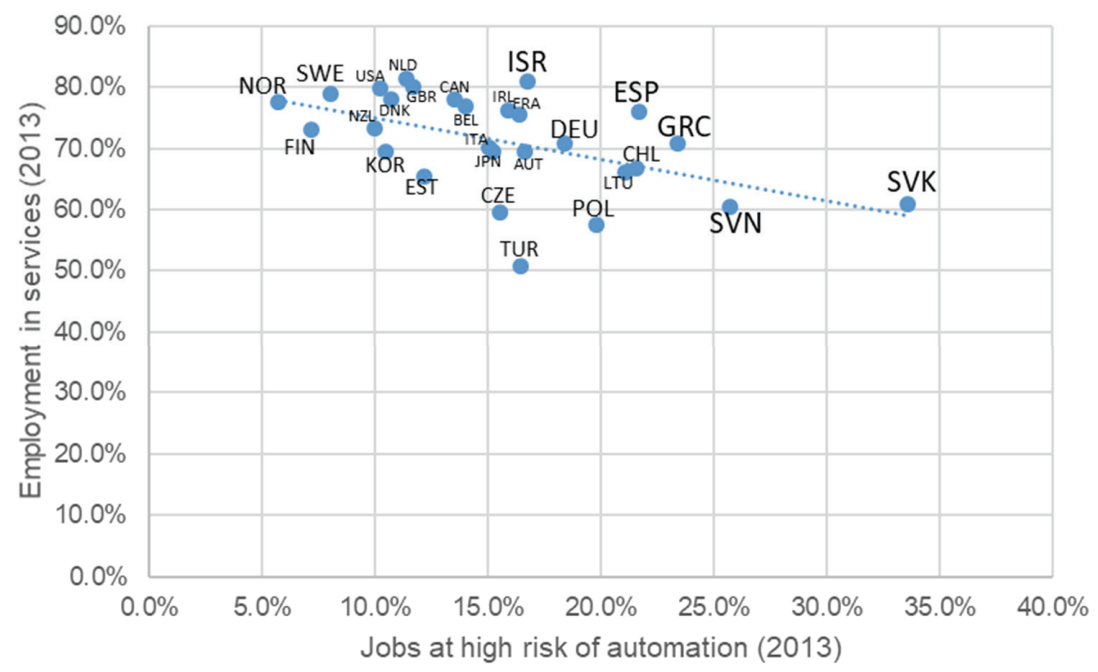

FIgURE 3 Relationship between the Percentage of Jobs at High Risk of Automation and the Percentage of Employment in Services

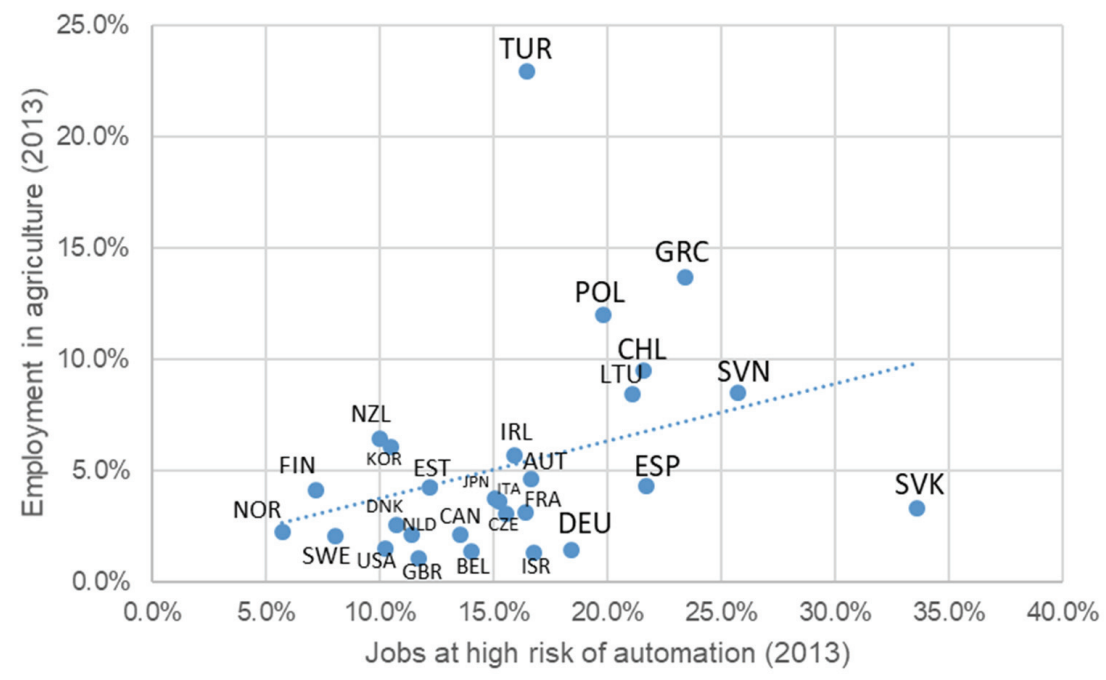

FIGURE 4 Relationship between the Percentage of Jobs at High Risk of Automation and the Percentage of Employment in Agriculture

there are more jobs in the service sector that are prone to automation in comparison with other countries like Poland, Czech Republic or Turkey. Countries that have highest employment in service sector and can be least vulnerable to job automation are Norway, Finland and Sweden. 
Based on our calculations, we can conclude that between variables that are shown in figure 4 , is only slightly moderate positive correlation. Correlation coefficient has a value of 0.33027 . The higher the employment in agriculture sector is, the higher is the risk of job automation in selected countries.

There are several specific countries, which can be seen in the figure 4. One of these countries is Turkey. In Turkey there is a risk of job automation at $16.4 \%$ and the employment in agriculture sector is $22.9 \%$. Another example is Slovakia, where the risk of job automation is at $33.6 \%$ and the employment is $3.3 \%$. In another words the automation can play a much different role in jobs in agricultural sector of economy in these countries. This means that jobs in agricultural sector in Slovakia can be more susceptible to automation than in Turkey. Another examples where this can also be the case, are countries like Slovenia, Greece, Poland, Chile, Lithuania and Spain in which aspects of jobs in agriculture sector that can be automated may vary. Countries where there is low employment in agriculture sector and also have low risk of job automation are Norway, Sweden and Finland.

Based on our calculations for the industry sector, if the employment in this sector is high then the risk of job automation is also high. On the contrary, if the employment in this sector is low than the risk of job automation is also low. In the service sector, according to our calculations if the employment in this sector is high then the risk of job automation is low and on the other hand if the employment in this sector is low then the risk of automation of jobs is high. In both cases, we can say that the most endangered countries in the terms of employment in the sectors of industry and services are Slovakia and Slovenia. The least endangered are the countries of Northern Europe - Norway, Sweden and Finland.

For the agricultural sector, only a slight positive correlation emerged. This means that with the growth of employment increases the risk of job automation. Measurements also showed a number of extremes, such as countries like Turkey and Slovakia. Therefore, we can assume that, in the case of several of these countries, automation may have a different impact on jobs. In Slovakia there can be more jobs that can be automated than in Turkey even though in Turkey there is a much higher employment in agriculture sector.

Based on our findings, we can say that the fourth industrial revolution, in short Industry 4.o, can have the same impact on employment in the sectors of industry and agriculture in the selected countries. In both cases if the employment in these sectors is high, the risk of job 
automation is also high. So countries with high employment in these sectors can be potentially mostly affected by automation. In the case of services sector if the employment is low in this sector the risk of job automation rises. Countries where the employment is low in this sector, face the potentially highest risk of job automation.

\section{Conclusion}

All industrial revolutions have had an impact on employment. This is also the case for the fourth industrial revolution. We live in a time that is characterized by rapid advances in the development of digital technologies. The core of these technologies is computer hardware, software and networks. Dramatics improvements in digital technologies make it possible to automate an increasing number of tasks and jobs. It is predicted that new digital technologies may have a negative impact on jobs and more and more jobs may become redundant. This phenomenon is also referred to as technological unemployment. Jobs that are least vulnerable to automation will be those that require social intelligence, creativity, and also require the use of new technologies. Redundant will be those jobs that are routine based, middle skilled and white collar.

The winners of this time will be those workers who have sufficient skills to work with new digital technologies and are able to adapt to the changing nature of the labour market. Those who do not have such skills can lose their jobs.

Potential winners and losers are unevenly positioned in the countries. Based on the calculations we performed, the correlation between the percentage risk of the automation of jobs and employment in the industrial sector is 0.45232 . This means that there is a moderate positive correlation between the examined variables. The higher the employment rate is in the industrial sector, the higher is the risk of job automation is selected countries. The correlation between the risk of automation and employment in the service sector is -0.52017 and therefore there is a moderate negative correlation. So we can say that the lower the employment in the service sector is, the higher is the risk of job automation. According to our calculations, the correlation between the risk of automation and employment in the agricultural sector is only slightly positive and has a value of 0.33027 . We can say that the higher the employment in the agricultural sector is, the risk of the automation of jobs in the countries rises. We can conclude that in countries such as Slovakia, Slovenia and Greece, the risk of job automation in all sectors of economy is the greatest. Countries which sectors of economy are potentially 
least affected by job automation are Norway, Sweden and Finland.

In our research, we have come up with research question: why is the correlation only moderate and not high. One reason why the correlation is only moderate and not high may be the fact that work that is easily automated in one country in another country may not be automated at all. Finding other reasons can be the basis for the further research.

In the end it should be noted that automation does substitute for labour. However, automation also complements labour, raises output in ways that lead to higher demand for labour, and interacts with adjustments in labour supply.

\section{Acknowledgements}

1/0152/18 VEGA Business and business models and platforms in the digital environment.

\section{References}

Acemoglu, D., and P. Restrepo. 2018. 'The Race between Man and Machine: Implications of Technology for Growth, Factor Shares, and Employment.' The American Economic Review 108 (6): 1488-542.

Autor, D. 2015. 'Why Are There Still So Many Jobs? The History and Future of Workplace Automation.' Journal of Economic Perspectives 29 (3): 3-30.

Brynjolfsson, E., and A. McAfee. 2014. The Second Machine Age. New York: Norton.

Corejova, T., and M. Al Kassiri. 2015. 'The Power of Knowledge-Intensive Services.' In 4th International Conference on Social Sciences and Society (Icsss 2015), edited by G. Lee and G. Schaefer, 1:354-57. Bellflower, cA: Information Engineering Research Institute.

- 2016. 'Knowledge as the Key to the Global Cooperation and Its Important Role Among Nations.' In 3rd International Conference on Power and Energy Systems Pes 2016, edited by G. Lee, 181-3. Bellflower, cA: Information Engineering Research Institute.

Freddi, D. 2018. 'Digitalisation and Employment in Manufacturing.' AI \& Soc 33 (3): 393-403.

Frey, C. B., and M. Osborne. 2013. 'The Future of Employment: How Susceptible are Jobs to Computerisation.' https://www.oxfordmartin.ox .ac.uk/downloads/academic/The_Future_of_Employment.pdf

Germany Trade \& Invest. 2014. 'Industrie 4.o Smart Manufacturing for the Future.' https://www.manufacturing-policy.eng.cam.ac.uk/ documents-folder/policies/germany-industrie-4-0-smart -manufacturing-for-the-future-gtai/view

Industrial Internet Consortium. 2017. 'A Global Industry First.' https:// www.iiconsortium.org/press-room/o4-20-17.htm 
Kagermann, H., R. Anderl, J. Gausemeier, and G. Schuh. 2016. Industrie 4.0 in a Global Context: Strategies for Cooperating with International Partners. Munich: Utz.

Kotynkova, M. 2016. 'Industry 4.o: Will the Concept Affect the World of Work?' Paper presented at the 14th International Scientific Conference: Economic Policy in the European Union Member Countries, Petrovice u Karviné, 14-16 September.

Madudova, M., T. Corejova, and M. Valica. 2018. 'Economic Sustainability in a Wider Context: Case Study of Considerable ICT Sector SubDivisions.' Sustainability 10 (7): 2511.

Marr, B. 2018. 'What is Industry 4.0? Here's A Super Easy Explanation For Anyone.' https://www.forbes.com/sites/bernardmarr/2018/o9/o2 /what-is-industry-4-o-heres-a-super-easy-explanation-for -anyone/\#500423d69788

Mokyr, J., Ch. Vickers, and N. Ziebarth. 2015. 'The History of Technological Anxiety and the Future of Economic Growth: Is This Time Different?' Journal of Economic Perspectives 29 (3): 31-50.

Nedelkoska, L., and G. Quintini. 2018. 'Automation, Skills Use and Training.' ofcd Social, Employment and Migration Working Papers 202, OECD Publishing, Paris.

OECD. 2018. 'Job Creation and Local Economic Development 2018 Preparing for the Future of Work.' https://www.oecd-ilibrary.org/ employment/job-creation-and-local-economic-development-2018 -9789264305342-en

Pfeiffer, S. 2016. 'Robots, Industry 4.o and Humans, or Why Assembly Work Is More than Routine Work.' Societies 6 (2): 16.

Rifkin, J. 2014. The Zero Marginal Cost Society, the Internet of Things, the Collaborative Commons, and the Eclipse of Capitalism. New York: Palgrave MacMillan.

Schwab, K. 2016. The Fourth Industrial Revolution. New York: Crown Business.

Trompisch, P. 2017. 'Industrie 4.o und die Zukunft der Arbeit. Elektrotech.' E\&I Elektrotechnik und Informationstechnik 134 (7): 370-3.

World Economic Forum. 2018. 'The Future of Jobs Report.' http://www3 .weforum.org/docs/WEF_Future_of_Jobs_2018.pdf 